\title{
Antibiotic susceptibility and pathogenicity of Aeromonas hydrophila isolated from red hybrid tilapia (Oreochromis niloticus $\times$ Oreochromis mossambicus) in Malaysia
}

\author{
Nurfarahin Ahmad Pauzi ${ }^{1}$ (D) Nurliyana Mohamad ${ }^{1}$ (D) Mohamad Azzam-Sayuti² ${ }^{(D)}$ Ina Salwany Md. Yasin ${ }^{2,3}$ (D), \\ Mohd Zamri Saad ${ }^{2,4}$, Nurrul Shaqinah Nasruddin ${ }^{5}$ iD and Mohammad Noor Amal Azmai ${ }^{1,2}$ (iD
}

1. Department of Biology, Faculty of Science, Universiti Putra Malaysia, 43400 UPM Serdang, Selangor, Malaysia; 2. Laboratory of Marine Biotechnology, Institute of Bioscience, Universiti Putra Malaysia, 43400 UPM Serdang, Selangor,

Malaysia; 3. Department of Aquaculture, Faculty of Agriculture, Universiti Putra Malaysia, 43400 UPM Serdang, Selangor, Malaysia; 4. Department of Veterinary Laboratory Diagnosis, Faculty of Veterinary Medicine, Universiti Putra Malaysia, 43400 UPM Serdang, Selangor, Malaysia; 5. Department of Clinical Oral Biology, Faculty of Dentistry, Universiti Kebangsaan Malaysia, Jalan Raja Muda Abdul Aziz, 50300 Kuala Lumpur, Malaysia.

Corresponding author: Nurliyana Mohamad, e-mail: m.nurliyana1990@gmail.com

Co-authors: NAP: farahinpauzi97@gmail.com, MA: azzamsayuti96@gmail.com, ISMY: salwany@upm.edu.my, MZS: mzamri@upm.edu.my, NSN: shaqinah@ukm.edu.my, MNAA: mnamal@upm.edu.my

Received: 09-05-2020, Accepted: 24-08-2020, Published online: 16-10-2020

doi: www.doi.org/10.14202/vetworld.2020.2166-2171 How to cite this article: Pauzi NA, Mohamad N, Azzam-Sayuti M, Yasin ISM, Saad MZ, Nasruddin NS, Azmai MNA (2020) Antibiotic susceptibility and pathogenicity of Aeromonas hydrophila isolated from red hybrid tilapia (Oreochromis niloticus $\times$ Oreochromis mossambicus) in Malaysia, Veterinary World, 13(10): 2166-2171.

\begin{abstract}
Background and Aim: Aeromonas hydrophila is a major cause of bacterial infections affecting a wide range of warm water fishes worldwide. In Malaysia, A. hydrophila isolations from diseased fishes were previously reported; however, with limited information. The present study investigates the antibiotic susceptibility and pathogenicity of $A$. hydrophila isolated from farmed red hybrid tilapia (Oreochromis spp.) in Malaysia.

Materials and Methods: $A$. hydrophila was biochemically identified and subjected to antibiotic susceptibility tests. The isolate was then intraperitoneally injected into red hybrid tilapia, and the mortality, clinicopathological changes, and $\mathrm{LD}_{50}$ were determined up to $240 \mathrm{~h}$ post-infection (hpi).

Results: The isolate demonstrated multiple antibiotic resistances (MAR) toward amikacin, ampicillin, cefotaxime, amoxicillin, trimethoprim-sulfamethoxazole, erythromycin, and streptomycin, with a MAR index of 0.5 . The experimental infection of $A$. hydrophila at $10^{5} \mathrm{CFU} / \mathrm{mL}$ in the red hybrid tilapia resulted in $100 \%$ mortality at 240 hpi. The LD $\mathrm{L}_{50}$ was determined at $1.1 \times 10^{4} \mathrm{CFU} / \mathrm{mL}$. Infected fish demonstrated occasional erratic swimming patterns, localized hemorrhages and depigmentation on the body and operculum areas, fin erosion, enlargement of the gall bladder, and hemorrhage in internal organs. Microscopic observation of infected fish revealed brain congestion, tubular necrosis, and glomerular shrinkage in the kidneys, necrosis of hepatocytes, and congestion of blood vessels in the liver.
\end{abstract}

Conclusion: The high virulence of $A$. hydrophila to the red hybrid tilapia emphasizes the importance of active, on-going monitoring of its prevalence in Malaysian tilapia farming.

Keywords: Aeromonas hydrophila, antibiotic sensitivity, aquaculture, pathogenicity, tilapia.

\section{Introduction}

Tilapia (Oreochromis spp.) is among the major commercially important freshwater fish intensively farmed worldwide. World tilapia production has exceeded 5 million tonnes, generating incomes of approximately USD 9.8 billion in 2015, and has been increasing annually [1]. In Malaysia, the production of tilapia in 2017 was approximately 31,400 tonnes with a wholesale value of RM 286 million, which indicates the significance of tilapia farming in the country [2]. Although tilapia culture is steadily

Copyright: Pauzi, et al. Open Access. This article is distributed under the terms of the Creative Commons Attribution 4.0 International License (http://creativecommons.org/licenses/by/4.0/), which permits unrestricted use, distribution, and reproduction in any medium, provided you give appropriate credit to the original author(s) and the source, provide a link to the Creative Commons license, and indicate if changes were made. The Creative Commons Public Domain Dedication waiver (http://creativecommons.org/ publicdomain/zero/1.0/) applies to the data made available in this article, unless otherwise stated. growing, the sector frequently suffers from disease outbreaks that represent a major obstacle to its growth. Aeromonas hydrophila is recognized as a significant pathogen which can have a devastating impact on the fish farming industry [3]; it can be potentially ubiquitous in both marine and freshwater environments, and under favorable conditions, it has emerged as an opportunistic pathogen. Infection by $A$. hydrophila is usually characterized by hemorrhagic ulcers on the skin and fin erosion [3]. It has been previously reported in various freshwater fish including channel catfish (Ictalurus punctatus), Siberian sturgeon (Acipenser baerii), Russian sturgeon (Acipenser gueldenstaedtii), banded knifefish (Gymnotus omarorum), and Nile tilapia (Oreochromis niloticus) [4-6].

In Malaysia, occurrences of $A$. hydrophila have been frequently reported in aquatic environments and retail fish [7-9]. Moreover, the infection of red hybrid tilapia (O. niloticus $\times$ Oreochromis mossambicus) and 
catfish (Clarias gariepinus) by $A$. hydrophila has also been previously described $[10,11]$. However, the pathogenicity of the Malaysian A. hydrophila isolate has never been investigated.

In this study, we determined the antibiotic susceptibility and pathogenicity of $A$. hydrophila isolated from red hybrid tilapia in Malaysia.

\section{Materials and Methods}

\section{Ethical approval}

The handling of fish and all experimental procedures, in this study, was performed in accordance with the methods approved by the Institutional Animal Care and Use Committee, Universiti Putra Malaysia (AUP No.: R006/2016).

\section{Study period and location}

The study was carried out for a period of 3 months from March until June 2019 at the Department of Biology, Faculty of Science, Universiti Putra Malaysia, Selangor, Malaysia.

\section{Bacterial strain}

The A. hydrophila isolate used in this study was obtained from the Aquatic Laboratory, Institute of Bioscience, Universiti Putra Malaysia, Malaysia. The isolate had been previously isolated from the spleen of diseased red hybrid tilapia and identified as $A$. hydrophila using biochemical and molecular methods [12]. Glycerol stock $\left(-80^{\circ} \mathrm{C}\right)$ of A. hydrophila was streaked on Tryptic Soy Agar (TSA) (Merck, Darmstadt, Germany) and incubated at $30^{\circ} \mathrm{C}$ for $24 \mathrm{~h}$. A pure colony of the isolate was subjected to Gram staining, catalase testing, oxidase testing, and the use of an API 20NE test kit (bioMérieux, Marcy l'Etoile, France) for species confirmation.

Following the positive confirmation of A. hydrophila, the isolate was then intraperitoneally (IP) injected into three red hybrid tilapias $\left(1 \mathrm{~mL}\right.$ at $10^{5}$ $\mathrm{CFU} / \mathrm{mL}$ of $A$. hydrophila per fish) for re-virulent purposes. The bacteria were re-isolated from moribund fish, cultured onto TSA, incubated at $30^{\circ} \mathrm{C}$ for $24 \mathrm{~h}$, and reconfirmed as $A$. hydrophila.

\section{Antibiotic susceptibility testing}

The A. hydrophila isolate was also subjected to antibiotic susceptibility tests, according to the guidelines proposed by the Clinical and Laboratory Standards Institute (CLSI) [13]. The commercial antibiotics used were amikacin $(30 \mu \mathrm{g})$, ampicillin $(10 \mu \mathrm{g})$, amoxicillin $(30 \mu \mathrm{g})$, levofloxacin $(5 \mu \mathrm{g})$, norfloxacin $(10 \mu \mathrm{g})$, cefotaxime $(30 \mu \mathrm{g})$, gentamicin $(10 \mu \mathrm{g})$, kanamycin $(30 \mu \mathrm{g})$, streptomycin $(30 \mu \mathrm{g})$, erythromycin $(15 \mu \mathrm{g})$, trimethoprim-sulfamethoxazole $(1.25 / 23.75 \mu \mathrm{g})$, chloramphenicol $(30 \mu \mathrm{g})$, tetracycline $(30 \mu \mathrm{g})$, and nalidixic acid $(30 \mu \mathrm{g})$ (Oxoid, London, UK). First, a fresh culture of $A$. hydrophila with a turbidity of $0.5 \mathrm{McF}$ arland was swabbed onto the surface of Mueller-Hinton agar (MHA) (HiMedia, Mumbai, India) using sterile cotton buds. The antibiotic disks were fixed on the MHA surface using sterile forceps, and the agar plates were incubated at $35^{\circ} \mathrm{C}$ for $24 \mathrm{~h}$. The inhibitory zones were interpreted according to the measurements provided by the CLSI guidelines [14]. The multiple antibiotic resistance (MAR) index was determined [15], and a MAR index value of $>0.2$ suggested a high-risk exposure to these antibiotics.

\section{Experimental infection study}

For the pathogenicity study, ten colonies of $24 \mathrm{~h}$ cultures of $A$. hydrophila were inoculated into $100 \mathrm{~mL}$ of Tryptic Soy Broth (TSB) (Merck) and incubated at $30^{\circ} \mathrm{C}$ for $24 \mathrm{~h}$. A ten-fold serial dilution was made with sterile TSB, and the standard spread-plate technique was used for bacterial enumeration.

One hundred eighty red hybrid tilapia (length: $9 \pm 2 \mathrm{~cm}$ ) were purchased from local suppliers and kept in a tank $(1500 \mathrm{~L})$ for 1 week for acclimatization. No sign of disease or mortality was observed during the acclimatization period. Five fish were randomly sampled, and their gills and body surfaces were examined microscopically for the presence of parasites. Swabs were taken from internal organs and tested for bacterial presence. The samples were determined to be free from parasite and bacterial infection. Before a challenge test, the fish were distributed into five treatment groups and one control group of 10 fish. The experiment was conducted in triplicate. The fish in each of the five treatment groups were IP injected with $1 \mathrm{~mL}$ of $A$. hydrophila at concentrations increasing from $10^{1}$ to $10^{5} \mathrm{CFU} / \mathrm{mL}$. The fish in the control group were injected with sterile TSB. Within $240 \mathrm{~h}$ post-infection (hpi), the clinical signs of gross lesions and mortality patterns were recorded, and the $\mathrm{LD}_{50}$ value was calculated [16]. Swabs were taken from the organs of the diseased red hybrid tilapia for isolation and identification of bacteria.

\section{Histopathological analysis}

The livers, brains, kidneys, and eyes of moribund fish were collected and preserved in $10 \%$ buffered formalin for histopathological analysis. Briefly, the organs were processed using a tissue processor (Leica TP 1020, Leica, Germany), embedded in paraffin, sectioned at $4 \mu \mathrm{m}$ thick (Leica Jung Multicut 2045, Germany), and stained with Harris's hematoxylin and eosin. The sections were then examined under a light microscope (Nikon Eclipse 50i, Japan) and analyzed using Nikon NIS-Element D 3.2 Image Analysis software (Nikon Instruments Inc., USA).

\section{Results}

Following identification using API 20NE, the result showed $99.9 \%$ similarity with $A$. hydrophila. The A. hydrophila isolate in this study formed yellowish, opaque colonies on TSA agar, produced beta-hemolysis on horse blood agar, and were motile, oxidase- and catalase-positive, and Gram-negative short rods (Table-1). The isolate tested positive for arginine dihydrolase and $\beta$-galactosidase, production 
of nitrate and indole, and hydrolysis of $\beta$-glucosidase and gelatin. It also assimilated arabinose, capric acid, glucose, malate, maltose, mannitol, mannose, $\mathrm{N}$-acetylglucosamine, and potassium gluconate.

The A. hydrophila isolate was sensitive to levofloxacin (inhibition zone: $24 \mathrm{~mm})$, gentamicin $(18 \mathrm{~mm})$, chloramphenicol $(23 \mathrm{~mm})$, tetracycline $(16 \mathrm{~mm})$, nalidixic acid $(23 \mathrm{~mm})$, kanamycin $(18 \mathrm{~mm})$, and norfloxacin $(22 \mathrm{~mm})$ and resistant to amikacin $(0 \mathrm{~mm})$, ampicillin $(0 \mathrm{~mm})$, cefotaxime $(14 \mathrm{~mm})$, amoxicillin $(0 \mathrm{~mm})$, trimethoprim-sulfamethoxazole $(0 \mathrm{~mm})$, erythromycin $(0 \mathrm{~mm})$, and streptomycin $(0 \mathrm{~mm})$.
In the pathogenicity study, the earliest mortality was observed at $6 \mathrm{hpi}$ in the groups infected with $10^{4} \mathrm{CFU} / \mathrm{mL}$ and $10^{5} \mathrm{CFU} / \mathrm{mL}$ of $A$. hydrophila (Figure-1). The highest cumulative mortality $(100 \%)$ was observed in the group infected with $10^{5} \mathrm{CFU} / \mathrm{mL}$, followed by group infected with $10^{4} \mathrm{CFU} / \mathrm{mL}(53.3 \%)$, $10^{3} \mathrm{CFU} / \mathrm{mL}(26.7 \%), 10^{2} \mathrm{CFU} / \mathrm{mL}(16.7 \%)$, and $10^{1}$ $\mathrm{CFU} / \mathrm{mL}(3.3 \%)$. In the present study, the calculated $\mathrm{LD}_{50}$ of $A$. hydrophila was $1.1 \times 10^{4} \mathrm{CFU} / \mathrm{mL}$.

Following IP injection, infected tilapia exhibited occasional erratic swimming patterns; hemorrhagic foci and depigmentation on body and operculum areas and

Table-1: Phenotypic and biochemical characteristics of $A$. hydrophila used in present study and its comparison with previously published $A$. hydrophila isolate.

Test Phenotypic and biochemical characteristics

\section{A. hydrophila (present study)}

Gram stain

Hemolysis (horse blood)

Oxidase

Catalase

Motility

Reduction of nitrates to nitrites

Indole production

Fermentation of glucose*

Arginine dihydrolase

Urease

Hydrolysis of $\beta$-glucosidase

Hydrolysis of protease (gelatin)

$\beta$-galactosidase

Assimilation of adipic acid*

Assimilation of arabinose

Assimilation of capric acid

Assimilation of glucose

Assimilation of malate

Assimilation of maltose

Assimilation of mannitol

Assimilation of mannose

Assimilation of ( $\mathrm{N}$-acetyl-Glucosamine)

Assimilation of phenylacetic acid

Assimilation of potassium gluconate

Assimilation of trisodium citrate
- (Short rod)
Beta-hemolysis

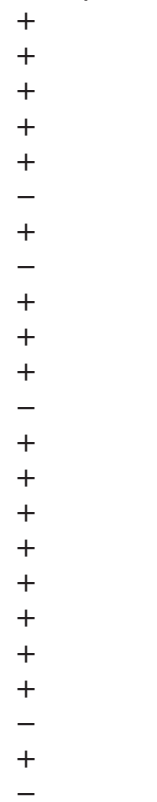

A. hydrophila [17]

- (Short rod)

Beta-hemolysis

$+$

$+$

$+$

$+$

$+$

$+$

NA

$+$

$+$

$+$

$+$

$+$

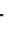

$+$

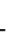

$+$

$+$

$-$

$+$

-

$+=$ Positive, $-=$ Negative, NA=Not available. All biochemical tests are included in the API 20NE. *Indicate difference of characteristics from previous study. A. hydrophila=Aeromonas hydrophila

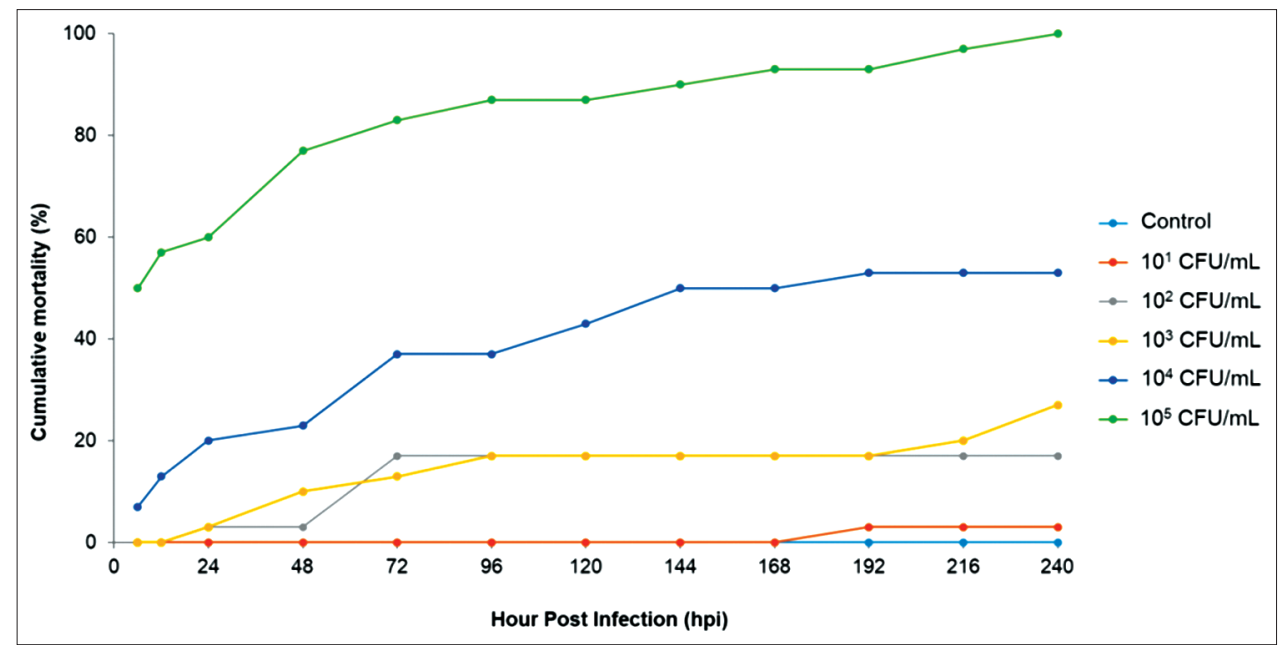

Figure-1: Mortality patterns of experimentally infected red hybrid tilapia with different concentration of Aeromonas hydrophila. No mortality was observed in control group injected with sterile Tryptic Soy Broth. 
tail erosion were also observed (Figure-2). Internally, infected fish demonstrated enlarged gall bladders and hemorrhage of internal organs. A. hydrophila was successfully isolated from the freshly dead fish.

Microscopic observation of infected red hybrid tilapia brain tissue revealed mild-to-moderate congestion (Figure-3). In addition, mild-to-moderate tubular necrosis and glomerular shrinkage in the kidneys and mild-to-moderate necrosis of hepatocytes and congestion of blood vessels in the livers of infected red hybrid tilapia were observed.

\section{Discussion}

This study reports the antibiotic susceptibility and pathogenicity of $A$. hydrophila isolated from diseased red hybrid tilapia in Malaysia. A. hydrophila has

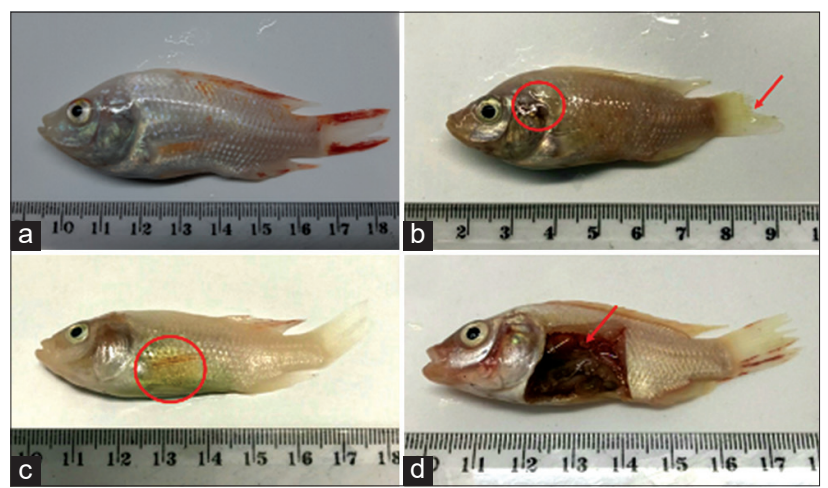

Figure-2: Clinical signs of red hybrid tilapia following Aeromonas hydrophila infection. (a) Healthy control fish showing no clinical signs and abnormalities; (b) hemorrhages around the operculum area (circle) and ulceration at caudal fin (arrow); (c) enlarged gall bladder; (d) intra-peritoneal hemorrhages.

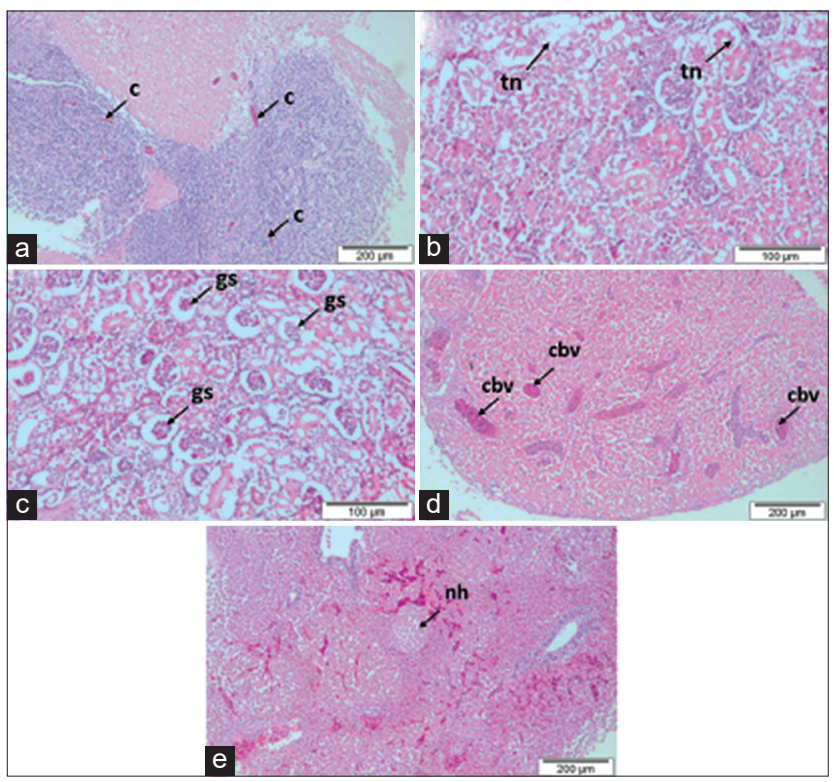

Figure-3: Histopathological changes of red hybrid tilapia infected by Aeromonas hydrophila. (a) Mild-moderate congestion (c) in brain; (b) mild-moderate tubular necrosis (tn) in the kidney; (c) mild observation of glomerular shrinkage (gs) in the kidney; (d) mild-moderate congestion of blood vessels (cbv) in the liver; (e) mild-moderate necrosis of the hepatocytes (nh) in the liver. been responsible for significant losses in the tilapia aquaculture industry worldwide. In Malaysia, its presence has been reported in the aquatic environment, retail, and cultured fish [7-10]; however, the pathogenicity of local $A$. hydrophila isolate has never been investigated.

The morphological and biochemical characteristics of A. hydrophila observed in this study are consistent with previous reports [17], except for its inability to ferment glucose and assimilate adipic acid. The isolate demonstrated multiple resistances toward the tested antibiotics including amikacin, ampicillin, cefotaxime, amoxicillin, trimethoprim-sulfamethoxazole, erythromycin, and streptomycin with a MAR index of 0.5. The resistance of $A$. hydrophila toward the penicillin group has been previously reported in Thailand [18], India [19], and Pakistan [17], probably due to the prolonged and excessive use of these antibiotics. Significantly, in this study, the quinolone group of antibiotics successfully inhibited the growth of A. hydrophila; hence, it can be utilized as a treatment in tilapia farms. However, with the concerns of newly emerging MAR pathogens, the responsible use of antibiotics in fish farming should be adopted, and alternative treatments to combat $A$. hydrophila infection should be applied.

The pathogenicity study revealed that red hybrid tilapia was susceptible to $A$. hydrophila infection following IP injection. The previous experimental studies on A. hydrophila infection in various hosts showed cumulative mortality ranging from $60 \%$ to $100 \%$, depending on the challenge doses and route of infection [20-23], which indicates a wide range of fish host susceptible to this pathogen. In this study, the $\mathrm{LD}_{50}$ was determined at $1.1 \times 10^{4} \mathrm{CFU} / \mathrm{mL}$, suggesting a low tolerance of red hybrid tilapia to $A$. hydrophila infection. In previous studies on the experimental infection of $A$. hydrophila using IP routes, the $\mathrm{LD}_{50}$ were recorded at $4.1 \times 10^{8} \mathrm{CFU} / \mathrm{mL}$ for snakehead fish (Channa striata) [23] and $4.53 \times 10^{6} \mathrm{CFU} / \mathrm{mL}$ for gourami (Osphronemus goramy) [22].

In the present study, the observed clinical signs were similar to those observed in affected catfish and Nile tilapia in natural outbreaks of $A$. hydrophila infection $[10,24]$ but with the lower severity. Other gross lesions such as exophthalmia and the presence of ascites caused by $A$. hydrophila infection in fish were not observed in this study $[10,24]$. Highly pathogenic strains may cause fish to die quickly without showing apparent signs of disease, as observed in this study where mortality started early at 6 hpi. In addition, other factors, such as the type and age of the host and the time of exposure, can also influence the severity of the clinical symptoms [5,6]. This study revealed that the kidneys of infected red hybrid tilapia showed tubular necrosis and glomerular shrinkage that was similar to previous reports $[10,25]$. Necrosis of the hepatocytes and congestion of blood vessels in the livers of infected red hybrid tilapia have 
also been observed in infected golden mahseer (Tor putitora) [26] and channel catfish [25].

\section{Conclusion}

This study demonstrates the susceptibility of red hybrid tilapia to A. hydrophila infection. Apart from its threat to cultured fish, the MAR of $A$. hydrophila isolates may also pose a health threat to humans. With respect to the potential pathogenicity of $A$. hydrophila to tilapia, more attention should be given to the diagnostics of the disease in farms and the effective control of this pathogen through the use of appropriate and environment-friendly therapeutic measures.

\section{Authors' Contributions}

NAP and MA conducted the experimental studies, analyzed and interpreted the data. NM, NSN, and MNAA contributed in the data interpretation. NM and MNAA drafted the manuscript. ISMY, MZS, NSN, and MNAA were involved in critical reading and editing. All authors read and approved the final manuscript.

\section{Acknowledgments}

This study was funded by Geran Putra Berimpak, Universiti Putra Malaysia (UPM/800-3/3/1/ GPB/2018/9668600).

\section{Competing Interests}

The authors declare that they have no competing interests.

\section{Publisher's Note}

Veterinary World remains neutral with regard to jurisdictional claims in published institutional affiliation.

\section{References}

1. Food and Agriculture Organization of the United Nations. (2017) FishStatJ, a Tool for Fishery Statistics Analysis. FAO Fisheries and Aquaculture Department, FIPS Statistics and Information, Rome. Available from: http://www.fao. org/fishery/statistics/software/fishstatj/en. Retrieved on 05-04-2020.

2. Annual Fisheries Statistic. (2018) Annual Fisheries Statistic. Department of Fisheries Malaysia, Ministry of Agriculture and Agro-Based Industry, Malaysia. Available from: https:// www.dof.gov.my. Retrieved on 05-04-2020.

3. Harikrishnan, R. and Balasundaram, C. (2005) Modern trends in Aeromonas hydrophila disease management with fish. Rev. Fish. Sci., 13(4): 281-320.

4. Aboyadak, I.M., Ali, N.G.M., Goda, A.M.A., Aboelgalagel, W.H. and Salam, A. (2015) Molecular detection of Aeromonas hydrophila as the main cause of outbreak in tilapia farms in Egypt. J Aquac. Mar. Biol., 2(6): 2-5.

5. Zhang, D., Xu, D.H. and Shoemaker, C. (2016) Experimental induction of motile Aeromonas septicemia in channel catfish (Ictalurus punctatus) by waterborne challenge with virulent Aeromonas hydrophila. Aquac. Rep., 3: 18-23.

6. Perretta, A., Antúnez, K. and Zunino, P. (2018) Phenotypic, molecular and pathological characterization of motile aeromonads isolated from diseased fishes cultured in Uruguay. J. Fish Dis., 41(10): 1559-1569.

7. Radu, S., Ahmad, N., Ling, F.H. and Reezal, A. (2003) Prevalence and resistance to antibiotics for Aeromonas species from retail fish in Malaysia. Int. J. Food Microbiol.,
81(3): 261-266.

8. Khor, W.C., Puah, S.M., Tan, J.A.M., Puthucheary, S.D. and Chua, K.H. (2015) Phenotypic and genetic diversity of Aeromonas species isolated from freshwater lakes in Malaysia. PLoS One, 10(12): e0145933.

9. Hamid, R., Ahmad, A. and Usup, G. (2016) Pathogenicity of Aeromonas hydrophila isolated from the Malaysian Sea against coral (Turbinaria sp.) and sea bass (Lates calcarifer). Environ. Sci. Pollut. Res., 23(17): 17269-17276.

10. Laith, A.R. and Najiah, M. (2013) Aeromonas hydrophila: Antimicrobial susceptibility and histopathology of isolates from diseased catfish, Clarias gariepinus (Burchell). $J$. Aquac. Res. Dev., 5(2): 1-7.

11. Lee, S.W. and Wendy, W. (2017) Antibiotic and heavy metal resistance of Aeromonas hydrophila and Edwardsiella tarda isolated from red hybrid tilapia (Oreochromis spp.) coinfected with motile aeromonas septicemia and edwardsiellosis. Vet. World, 10(7): 803.

12. Saleema, M. (2015) Molecular Characterization of Aeromonas hydrophila and Development of Recombinant Cells Vaccine Expressing outer Membrane Proteins against its in African Catfish (Clarias gariepinus Burchell) (Unpublished Master Thesis), Universiti Putra Malaysia, Malaysia.

13. Clinical and Laboratory Standards Institute. (2016) Methods for Dilution Antimicrobial Dilution and Disk Susceptibility Testing of Infrequently Isolated or Fastidious Bacteria; Approved Guideline. $3^{\text {rd }}$ ed. Clinical and Laboratory Standards Institute, Wayne, Pennsylvania, USA. Available from: https://www.clsi.org. Retrieved on 05-04-2020.

14. Clinical and Laboratory Standards Institute. (2013) Performance standards for Antimicrobial Susceptibility Testing; Twenty-third informational supplement. CLSI document M100-S23. Clinical and Laboratory Standards Institute, Wayne, Pennsylvania, USA. Available from: https://www.clsi.org. Retrieved on 03-07-2019.

15. Krumperman, P.H. (1985) Multiple antibiotic indexing of E. coli to identify high-risk sources of fecal contamination of foods. Appl. Environ. Microbiol., 46(1): 65-170.

16. Reed, L.J. and Muench, H. (1938) A simple method of estimating fifty percent endpoints. Am. J. Epidemiol., 27(3): 493-497.

17. Ali, S., Akhter, S., Muhammad, A., Khan, I., Khan, W.A., Iqbal, M.N., Umar, S., Ahmed, H. and Ali, Q. (2016) Identification, characterization and antibiotic sensitivity of Aeromonas hydrophila, a causative agent of epizootic ulcerative syndrome in wild and farmed fish from Potohar, Pakistan. Pak. J. Zool., 48(3): 899-901.

18. Tipmongkolsilp, N., del Castillo, C.S., Hikima, J.I., Jung, T.S., Kondo, H., Hirono, I. and Aoki, T. (2012) Multiple drug-resistant strains of Aeromonas hydrophila isolated from tilapia farms in Thailand. Fish Pathol., 47(2): 56-63.

19. Samal, S.K., Das, B.K. and Pal, B.B. (2014) Isolation, biochemical characterization, antibiotic susceptibility study of Aeromonas hydrophila isolated from freshwater fish. Int. J. Curr. Microbiol. Appl. Sci., 3(12): 259-267.

20. Hossain, M.F., Rashid, M.M. and Sayed, M.A. (2011) Experimental infection of indigenous climbing perch (Anabas testudineus) with Aeromonas hydrophila bacteria. Prog. Agric., 22(1-2): 105-114.

21. Dias, M.K.R., Sampaio, L.S., Proietti-Junior, A.A., Yoshioka, E.T.O., Rodrigues, D.P., Rodriguez, A.F.R. and Tavares-Dias, M. (2016) Lethal dose and clinical signs of Aeromonas hydrophila in Arapaima gigas (Arapaimidae), the giant fish from Amazon. Vet. Microbiol., 188(5): 12-15.

22. Rozi, Rahayu, K., Daruti, D.N. and Stella M.S.P. (2018) Study on characterization, pathogenicity and histopathology of disease caused by Aeromonas hydrophila in gourami (Osphronemus gouramy). Earth Environ. Sci., 137: 12003.

23. Samayanpaulraj, V., Velu, V. and Uthandakalaipandiyan, R. (2019) Determination of lethal dose of Aeromonas 
hydrophila Ah17 strain in snake head fish Channa striata. Microb. Pathog., 127(2): 7-11.

24. El Deen, A.N., Dorgham-Sohad, M., Hassan-Azza, H.M. and Hakim, A.S. (2014) Studies on Aeromonas hydrophila in cultured Oreochromis niloticus at Kafr El Sheikh Governorate, Egypt with reference to histopathological alterations in some vital organs. World J. Fish Mar. Sci., 6(3): $233-240$

25. Abdelhamed, H., Ibrahim, I., Baumgartner, W.,
Lawrence, M.L. and Karsi, A. (2017) Characterization of histopathological and ultrastructural changes in channel catfish experimentally infected with virulent Aeromonas hydrophila. Front. Microbiol., 8: 1519.

26. Kumar, R., Pande, V., Singh, L., Sharma, L., Saxena, N., Thakuria, D., Singh, A.K. and Sahoo, P.K. (2016) Pathological findings of experimental Aeromonas hydrophila infection in golden mahseer (Tor putitora). Fish. Aquac. J., 7(160): 1-6.

$* * * * * * * *$ 